\title{
PRINCÍPIOS E REQUISITOS DE USABILIDADE NA CONCEPÇÃO DE UMA FERRAMENTA DE SUPORTE À GESTÃO DE DESIGN
}

\section{PRINCIPLES AND REQUIREMENTS OF USABILITY IN THE DESIGN OF TOOL TO DESIGN MANAGEMENT}

\author{
SILVA, Carina Scandolara da (1); \\ MERINO, Eugenio Díaz (2); \\ MERINO, Giselle Schmidt Alvez Díaz (3); \\ FIGUEIREDO, Luiz Fernando Gonçalves de (4) \\ (1) Universidade Federal de Santa Catarina, Mestre \\ e-mail: cariscan@gmail.com \\ (2) Universidade Federal de Santa Catarina, Doutor \\ e-mail: eugenio.merino@ufsc.br \\ (3) Universidade Federal de Santa Catarina, Doutora \\ e-mail: gisellemerino@gmail.com \\ (4) Universidade Federal de Santa Catarina, Doutor \\ e-mail: Iff@cce.ufsc.br
}

\begin{abstract}
RESUMO
A gestão de design é uma área que necessita de ferramentas operacionais para o seu gerenciamento. As orientações de usabilidade da NBR ISO 9241-11 e os princípios de usabilidade de Jordan estabelecem medidas e exigências para concepção de uma ferramenta de gestão de design. Para levantar as informações, e compreender o funcionamento e as necessidades da gestão de design, foi realizado um estudo de caso em um estúdio de design. A partir do conhecimento do contexto de uso e dos objetivos da ferramenta, foram estabelecidos os requisitos e as medidas de usabilidade e, posteriormente, a partir dos princípios de Jordan, foram elencadas as exigências de usabilidade. Com isso, espera-se que a ferramenta privilegie o conforto e a usabilidade dos usuários no contexto da gestão de design.
\end{abstract}

Palavras-chave: Usabilidade; Princípios de usabilidade; Requisitos de Usabilidade; Gestão de Design

\section{ABSTRACT}

The design management is an area that requires operational tools for its management. The usability of ISO 9241-11 guidelines and principles of Jordan usability establish measures and requirements for design of a design management tool. To elicit information, and understand the operation and design management needs, we conducted a case study in a design studio. From the knowledge of the context of 
use and the tool's objectives, requirements and usability measures were established and, subsequently, from the principles of Jordan, were listed usability requirements. Thus, it is expected that the tool favoring the comfort and usability of users in the context of design management.

Keywords: Usability; Usability principles; Usability Requirements; Design Management

\section{INTRODUÇÃO}

Desenvolver produtos adequados aos usuários deste sua concepção, levando-se em conta não apenas as suas funcionalidades e desempenho, mas também o conforto e a satisfação dos usuários é uma necessidade e um desafio. A usabilidade pode trazer princípios e requisitos que podem colaborar com este desenvolvimento.

De acordo com a NR ISO 9241-11 "planejar para usabilidade, como parte de um projeto e desenvolvimento de produtos, envolve uma identificação sistemática de requisitos para usabilidade, incluindo medidas de usabilidade e descrições verificáveis do contexto de uso. Estas fornecem metas de projeto que podem servir de base para a verificação do projeto resultante." Para o desenvolvimento da ferramenta de gestão de design que será proposta, serão levados em consideração o processo de design produtos para usabilidade proposto por Jodan(1998), bem como as orientações de usabilidade da NBR ISO 9241-11 e, por último, os princípios de usabilidade de Jordan (1998), que delineiam como cada item pode afetar a usabilidade em uma interface.

A necessidade de uma ferramenta de apoio à gestão de design foi identificada em um estudo elaborado por Silva (2012), em que estudava a abordagem sistêmica com foco na gestão de design sustentável. Constatou-se que a maioria das ferramentas disponíveis adequadas ao gerenciamento de design são as ferramentas voltadas para desenvolvimento de projetos em geral, seja qual for a área. Desta forma, o objetivo da pesquisa foi estabelecer princípios e requisitos de usabilidade para a concepção de uma ferramenta de gestão de design que atenda às necessidades dos usuários deste contexto.

Silva (2012) levantou, por meio de um mapeamento da gestão de design as primeiras necessidades dos usuários em relação a uma ferramenta que visasse melhorar o ambiente, facilitasse o controle e o acesso às informações concernentes aos projetos, objetivos e estratégias da empresa. A partir disso, buscou-se estabelecer os requisitos e os princípios de usabilidade para desenvolver uma ferramenta que solucione as problemáticas encontradas. $\mathrm{O}$ estudo atual se deu por meio de estudo de caso em um estúdio de design, o mesmo estudado por Silva (2012), sendo uma continuidade da pesquisa.

O resultado que se esperava com esta pesquisa é o levantamento de requisitos de usabilidade de acordo com a NBR ISO 9241-11, assim como uma relação das exisgências de usabilidade segundo os princípios de usabilidade de Jordan (1998), que possam servir de suporte para ao desenvolvimento uma ferramenta de gestão de design. 


\section{USABILIDADE NA CONCEPÇÃO DE PRODUTOS}

A usabilidade pode ser considerada deste princípio de concepção de um produto. Ela surgiu no contexto de ergonomia de interface humano-computador e, ao longo dos últimos anos vem evoluindo para considerar os produtos de forma geral (CYBIS ET AL, 2010). É definida como sendo a "medida na qual um produto pode ser usado por usuários específicos para alcançar objetivos específicos com eficácia, eficiência e satisfação em um contexto específico de uso." (NBR 9241-11, 2002: 3)

Para o melhor compreensão do conceito, é importante conhecer o significado dos seguintes termos, conforme Jordan (1998):

- Eficácia: se refere à extensão na qual uma meta é alcançada ou uma tarefa é realizada.

- Eficiência: se refere à quantidade de esforço requerido para se atingir uma meta. Quanto menos esforço, maior é a eficiência.

- Satisfação: se refere ao nível de conforto que os usuários sentem quando utilizam um produto e também ao nível de aceitação do produto pelos usuários para atingir as suas metas.

Diversos autores conceituam a usabilidade, cada um com sua especificidade. Porém, o que se pode deduzir é que buscam como resultado um produto que atenda às necessidades dos usuários, além de sustentarem que é possível planejar o resultado pretendido.

De acordo com a NBR ISO 9241-11 (2002:4), "planejar para usabilidade, como parte de um projeto e desenvolvimento de produtos, envolve uma identificação sistemática de requisitos para usabilidade, incluindo medidas de usabilidade e descrições verificáveis do contexto de uso. Estas fornecem metas de projeto que podem servir de base para a verificação do projeto resultante." A norma também organiza uma estrutura para especificar a usabilidade que orienta como descrever a proposta do produto, os componentes de usabilidade, os objetivos, 0 contexto de uso e as medidas de usabilidade.

Figura 1: Estrutura de usabilidade NBR ISO

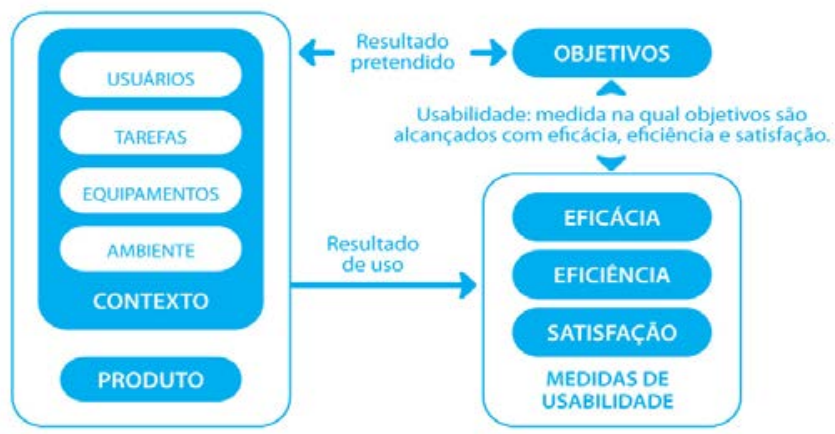

Fonte: NBR ISO 9241-11 (2002:4)

A figura 1 mostra o diagrama com a estrutura de usabilidade sugerida pela NBR ISO 9241-11 (2002), mostrando o ciclo que o produto deve atender. Na primeira coluna, constam os itens 
que devem ser descritos e que vão fornecer as informações necessárias para desenvolver um produto segundo seu objetivo pretendido e que tenha eficácia, eficiência e proporcione satisfação ao usuário.

No processo de desenvolvimento de design para usabilidade, Jordan (1998) trata a prática com uma abordagem centrada no usuário e sugere alguns passos: 1) Especificação de características dos usuários; 2) Definição de requisitos; 3) Especificações de usabilidade; e 4) Design interativo e prototipagem. Os três primeiros passos tratam do levantamento de informação, abordados nesta pesquisa.

Jordan (1998) sugere princípios que delineiam como cada um deles pode afetar a usabilidade em uma interface. São eles: consistência, compatibilidade, capacidade, retroalimentação, prevenção ou correção de erros, controle do usuário, clareza visual, priorização da funcionalidade e da informação, transferência adequada de tecnologia e evidência. A especificação das exigências baseadas nos princípios de usabilidade colaboram para a concepção de um produto centrado no usuário e no conforto de seu uso.

Para o levantamento das informações sobre o contexto da gestão de design, houve o processo de compreensão do seu conceito e funcionamento, conhecendo os usuários e suas tarefas, o ambiente e os equipamentos, bem como o levantamento das necessidades e objetivos.

\section{GESTÃO DE DESIGN}

A Gestão de Design caracteriza-se por um "conjunto de técnicas de gestão empresarial dirigidas a maximizar, ao menor custo possível, a competitividade que a empresa obtém pela incorporação e utilização do design industrial como instrumento de sua estratégia organizacional" (GIMENO, 2000, p. 25). E tem como papel "a implantação do design na empresa para ajudar a construir sua estratégia, o que implica na: i) gestão de integração do design na empresa em nível operacional do projeto, organizacional da função ou estratégico da missão; e ii) na gestão do sistema de design da empresa" (MOZOTA, 2002, p.86). A gestão de design é dividida por Best (2009) e Mozota (2003) em três níveis: o estratégico, o tático e o operacional. Sendo que:

- O nível estratégico, ou a habilidade de design para unificar e transformar a visão da organização, define as diretrizes, as missões e o planejamento;

- O nível tático ou funcional, ou a criação de uma função de design na organização, é representado pelas equipes, pelo processo e pelas funções específicas necessárias;

- O nível operacional de projeto, ou o primeiro passo para o design integrado, se manifesta nos produtos e serviços que o consumidor vai poder se apropriar.

Figura 2: Componentes do sistemas em cada nível de gestão de design para Best (2009) e Mozota (2003) 


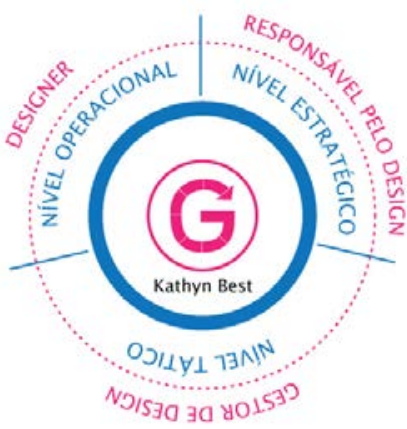

Fonte: Adaptado de Best (2009) e Mozota (2003)

A figura 2 mostra os componentes e os níveis da gestão de design no qual atuam, desta forma facilita a compreensão e a associação entre o componente e o seu nível de atuação. Estes são os componentes principais da gestão de design. Cada um possui papel de destaque nas tarefas e em todo o fluxo de desenvolvimento das atividades.

A pesquisa realizada por Silva (2012), em que aplicou a abordagem sistêmica para a gestão de design sustentável, teve como um dos resultados mapeamento da gestão de design de um estúdio de design. A pesquisa se realizou por meio de um estudo de caso. Silva (2012) identificou os componentes da gestão de design apresentados por Mozota (2003) e Best (2009): responsável pelo design, gestor de design e o designer. Além destes, ela também encontrou outros componentes que, apesar de não executam os principais papéis, também estão presentes: administrativo/ financeiro, atendimento (comercial), produção e limpeza. Além dos componentes, também identificou as interações existentes e suas tarefas.

Compreender a gestão de design, suas interações e sistemática de funcionamento colaborou para o levantamento das informações necessárias para o desenvolvimento de uma ferramenta de gestão de design. A seguir, apresentam-se os procedimentos metodológicos adotados.

\section{PROCEDIMENTOS METOLOLÓGICOS}

A pesquisa desenvolvida se caracteriza, conforme Gil (2010), por ser do tipo aplicada, que gera conhecimentos para aplicação prática e dirigidos à solução de problemas específicos. Tem abordagem qualitativa e objetivo exploratório, visando obter maior familiaridade com 0 problema, explicitando-o. Ela busca reunir informações gerais sobre o objeto de estudo.

Quanto aos procedimentos técnicos, conforme Gil (2010), trata-se de um estudo de caso, envolvendo estudo aprofundado sobre a gestão de design do caso estudado, afim de estabelecer princípios e requisitos de usabilidade para concepção de uma ferramenta de gestão de design. O caso estudado é uma empresa ${ }^{1}$ de pequeno porte de design, localizada em Florianópolis, com dez colaboradores. A pesquisa atual é uma continuidade do estudo de Silva

1

www.nuovo.com.br

$\square$ Nuovo Design (www.nuovo.com.br) 
(2012) e tomou como referência o levantamento de informações realizado por meio do mapeamento da gestão de design, onde constam os componentes relacionados à gestão de design, suas interações e tarefas. No entanto o foco que se deu nesta nova pesquisa foi na busca dos princípios e requisitos de usabilidade para o desenvolvimento de uma ferramenta de suporte à gestão de design.

A coletada de dados se deu por meio de observação participante entre os períodos de setembro à novembro de 2013 - para levantar as informações sobre o contexto de uso da ferramenta - e por grupos focais, em que integrantes da gestão de design do estúdio, de ocupações diferentes entre si, colaboraram para identificar problemas e possíveis soluções para os mesmos. Desta forma, foi definido o objetivo da ferramenta de gestão de design e, a partir disso, requisitos e medidas de usabilidade, conforme NBR ISO 9241-11. Posteriormente, foram realizadas novas sessões de grupos focais para especificas as exigências de usabilidade com base nos princípios de Jordan (1998). A partir disso, levantou-se toda a informação necessária para colaborar com o desenvolvimento da ferramenta de gestão de design.

\section{FERRAMENTA DE GESTÃO DE DESIGN: PRINCÍPIOS E REQUISITOS DE USABILIDADE}

Esta pesquisa contempla a especificação das características dos usuários e o contexto de uso da ferramenta de gestão de design, para posterior definição de requisitos e especificação de usabilidade para, conforme Jordan (1998). Além disso, serão seguidas as orientações de especificação de contexto de uso, que inclui a especificação dos usuários e tarefas, do ambiente e dos equipamentos para a ferramenta a ser desenvolvida da NBR ISO 9241-11, que oferece um modelo de estrutura para esta atividade, com orientações sobre cada item, exemplificando como elaborar as especificações e as medidas para usabilidade.

\subsection{Objetivo}

A partir das informações levantadas por Silva (2012) e, principalmente, por meio de observação participante, bem como a realização de grupos focais com integrantes da gestão de design caso estudado, foram identificadas as necessidades e consequentemente, elaborados os objetivos pretendidos com a ferramenta. O objetivo é conceber uma ferramenta de suporte à gestão de design, que controle todas suas etapas, deste a concepção de estratégias para desenvolvimento de projetos de design até suas etapas finais de entrega e retorno sobre a satisfação com o produto ou serviço executado. Que possa facilitar o trabalho dos componentes envolvidos na gestão de design, principalmente do gestor de design e do designer, que executam a maior parte das tarefas práticas concernentes à gestão de design. Que a ferramenta tenha como objetivo final ajudar a tornar a gestão de design mais eficaz (agilizar o processo), eficiente (trazer maior qualidade ao processo, menor incidência de erros etc.) e traga maior satisfação na execução das tarefas. Após a definição dos objetivos com o produto, iniciou-se a identificação e especificação do contexto de uso.

\subsection{Especificação do contexto de uso}

$\mathrm{Na}$ especificação do contexto de uso, o modelo da NBR ISO 9241-11 orientou as etapas e as necessidades. Ele estabelece que o contexto de uso é formado pelos usuários, as tarefas, 0 ambiente e os equipamentos, ilustrados na figura 3: 
Figura 3: Diagrama da composição do contexto de uso de um produto

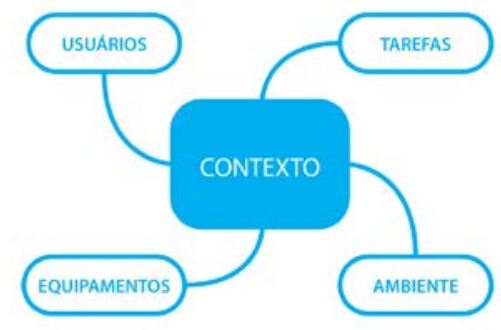

Fonte: Elaborado pelo autor

Na especificação do contexto, cada item (usuários e tarefas, equipamentos e ambiente) vai ser abordado em detalhe e a partir disso serão elaboradas as especificações de usabilidade para o contexto de uso.

\subsubsection{Usuários e tarefas}

Silva (2012) identifica seis tipos de usuários para a ferramenta de gestão de design, sendo eles: o designer, o gestor de design, o cliente (responsável pelo design), o administrativo/ financeiro, o comercial e a produção. O setor de limpeza será excluído por não ter interação suficiente com a gestão de design que justifique acesso à ferramenta. Por meio de observação participante, foram especificados, para cada usuário da ferramenta, o seu perfil e suas atividades (tarefas):

- Designer: usuário que desenvolve os projetos de design. Tem formação em design ou em uma área afim. Possui conhecimento em mídias digitais, de softwares de alta complexidade de funcionamento, conhecimento em desenvolvimento de projetos de interação. Está atualizado com as últimas novidades da área de design e das mídias em geral. Podem sugerir boas ideias para desenvolver uma interface amigável e soluções visuais para isso. Trabalham a maior parte do seu tempo em frente ao computador em mesas individuais ou compartilhadas, reunindo-se a cada novo projeto ou, em fases intermediárias, com o gestor de design, com a equipe de designers e, para dar suporte de qualidade à produção.

- Gestor de design: usuário que gerencia o design dos projetos. Tem formação em design ou alguma área afim, em geral, com alguma especialização. Acompanha o ciclo do projeto junto aos componentes da gestão de design, passando briefing de projeto para a equipe de designers, analisando projetos em desenvolvimento, tomando decisões de fechamento dos projetos para apresentação e, muitas vezes, apresentando os projetos ao responsável pelo design (cliente). Tem conhecimento geral sobre as mídias e tecnologias. Conhece as tecnologias que envolvem o design e suas possibilidades, utiliza metodologias de projeto e de processo em seu trabalho. Usa computador em sua rotina, mas também passa muitas horas em reunião com a equipe de designers, com 0 comercial e com o responsável pelo design, intermediando as relações, as informações e os projetos.

- Responsável pelo design: usuário responsável pela avaliação e aprovação final do projeto de design, pelas definições estratégicas junto aos clientes e por gerir as relações 
entre produto/ serviço e cliente. Em alguns casos, este usuário está fora da entidade executora do design, ficando localizado na empresa que contratou os serviços de design.

- Financeiro: o usuário responsável pelo financeiro é responsável por inserir valores e horas que foram especificados em cada projeto. Pode inserir também descritivo de projeto de propostas ou contratos de trabalho. Controla a relação custo $X$ hora de trabalho.

- Comercial: o usuário do comercial é responsável por especificar a demanda de projeto, com base no que é vendido ao cliente. Também é responsável por identificar necessidades no mercado. O usuário tem um perfil comunicativo, com facilidade de uso de tecnologias e ferramentas de comunicação como email, mídias sociais, chat, editores de texto e dispositivos tecnológicos móveis. Atua bastante tempo no rua, em pontos-devenda, nos clientes. Tem o perfil de se deslocar durante seu trabalho, assim como de realizar reuniões para vendas e fechamento de negócios.

- Produção: o usuário de produção é responsável por gerenciar a produção dos projetos de design. Tem muito contato com fornecedores terceirizados, acompanha o envio de arquivos, as provas ou mockups a qualidade do material, o prazo de entrega. Tem o perfil de usar ferramentas de comunicação com email, telefone e chats com os fornecedores. Se desloca pouco da entidade executora, com exceção de alguma prova que precise ser acompanhada no produtor terceirizado. Faz reuniões com o gestor de design e com o designer para certificação de qualidade da produção e encaminha materiais para o responsável pelo design dar aprovação final.

\subsubsection{Equipamentos}

Para esta ferramenta de gestão de design, pensou-se em um sistema via web, que possa ser executado em navegadores de internet. Por este motivo, é necessário o uso de um equipamento com acesso à internet, podendo ser: computador de mesa, notebook ou plataformas mobile (tablet, smartphone, PDA etc.). O sistema será independente de sistema operacional e não será necessário a instalação de qualquer software hardware na estação do usuário.

Por ser um sistema via web, mais importante que o hardware é a velocidade de banda da internet. Um vez que o desempenho do sistema dependerá diretamente do tamanho da banda de acesso à Internet dedicado à estação de trabalho. Recomenda-se que a estação tenha, no mínimo, uma banda de acesso dedicado de $1 \mathrm{Gbps}$. Valores abaixo do especificado poderão causar lentidão no uso do sistema.

\subsubsection{Ambiente}

O caso que vem sendo estudado é um estúdio (MPE) de design, que realiza projetos nas áreas de design gráfico, design de produto e design digital, realizando também consultorias em design. Tem como colaboradores pessoas formadas em design, artes gráficas, sistemas de informação e jornalismo. A carga horária de trabalho é de 8h diárias, que se iniciam às 9:00h até 19:00h com intervalo de $2 \mathrm{~h}$ para o almoço, das 12:00h às 14:00h. 
O ambiente físico e atmosférico é composto de uma sala de aproximadamente $4,5 \times 11 \mathrm{~m}^{2}$, com três janelas grandes com vidros que vão até a altura do joelho, que precisam de cortinas para bloquear o sol em certos horários. As janelas precisam ficar a maior parte do tempo fechadas em virtude da poluição sonora que existe na região, com uma avenida de grande movimentação em frente ao estúdio. Em relação ao ambiente atmosférico, a temperatura é mantida por meio de condicionadores de ar. No entanto, quando o sol bate nas janelas, as mesas que ficam perto tem uma maior incidência de calor, apesar das cortinas.

O ambiente interno é dividido com semi-divisórias (paredes baixas, estante de livros, espelho etc.) usadas para demarcar espaços como área de reunião, financeiro, área de desenvolvimento de projetos, área de trabalhos manuais, área de alimentação e café. Os únicos espaços completamente separados são a cozinha e o banheiro. $\mathrm{Na}$ área de desenvolvimento de projeto existem duas mesas grandes para os designers, com quatro estações de trabalho em cada mesa, há uma mesa com dois espaços para o gestor de design e para o comercial, com local para se reunir com uma ou duas pessoas e espaço para conexão de computador portátil (notebook). A área de financeiro é uma estação fixa em um módulo separado. Existe uma área para execução de trabalhos manuais, como montagem de mockups e desenho, que é usada principalmente pelos designers. Na área de reunião, existe uma mesa maior para até seis pessoas, onde as equipes fazem as reuniões de pauta semanal e os projetos são apresentados aos clientes.

No ambiente cultural e social, a estrutura organizacional foi concebida de forma integrada, com todos os componentes trabalhando próximos uns aos outros, o que proporciona facilidade de comunicação e interação entre si. Esta aproximação física ajuda a reduzir o distanciamento entre as pessoas que desempenham tarefas com menor afinidade, por exemplo entre designer e comercial. Também faz com que haja além das trocas relacionadas aos projetos, as trocas de experiências pessoais e conversas informais. A área de café que fica próxima e, quando há a parada para um café, os integrantes da equipe podem conversar e trocar informações informalmente. O clima de trabalho, em geral, é leve, no entanto existem projetos que exigem mais dos colaboradores, o que faz o nível de concentração se fazer mais necessário e haver redução de interação. Também há momentos, quando se tem pessoas externas (clientes, fornecedores, estudantes etc.) ou muitas ligações telefônicas, o ambiente pode ser tornar um pouco caótico, em virtude da integração.

Por meio da especificação do contexto de uso, foi possível identificar as necessidades da ferramenta e especificar diversos requisitos. A seguir serão vistas as medidas de usabilidade e as especificações de exigência para interface que também vão orientar a concepção da ferramenta.

\subsection{Especificação de requisitos de usabilidade: medidas e exigências para interface}

De acordo com a NBR ISO 9241-11, planejar para usabilidade envolve a identificação dos requisitos para usabilidade, incluindo medidas de usabilidade e descrições verificáveis do contexto de uso. Estas fornecem metas de projeto que podem servir de base para a verificação do projeto resultante. Na pesquisa foram tomados como base os objetivos da ferramenta para gerar as especificações de medidas de usabilidade de eficácia, eficiência e satisfação. As medidas de usabilidade foram encontradas por meio das sessões de grupos focais com os 
integrantes da gestão de design. Para compreender como foram geradas as especificações, é importante compreender o significado de cada medida, conforme a NBR ISO 9241-11 (figura $X X)$ a seguir.

Figura : Diagrama com as definições de eficácia, eficiência e satisfação para a usabilidade

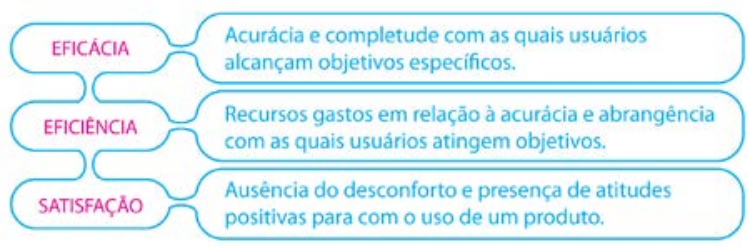

Fonte: Adaptado da NBR ISO 9241-11

De acordo com a NBR ISO 9241-11, ao selecionar medidas de usabilidade para os objetivos mais importantes do usuário pode ser necessário ignorar muitas funções, mas provavelmente esta seja a abordagem mais prática. Neste primeiro levantamento de informações, foram selecionados alguns pontos globais para especificar as medidas de usabilidade. A seguir, a tabela 1 apresenta as medidas de usabilidade extraídas a partir da pesquisa junto ao caso estudado, por meio de grupos focais com integrantes da gestão de design.

Tabela 1: Medidas de eficácia, eficiência e satisfação para a usabilidade

\begin{tabular}{|c|c|c|c|}
\hline $\begin{array}{l}\text { Objetivos de } \\
\text { usabilidade }\end{array}$ & Medidas de eficácia & Medidas de eficiência & Medidas de satisfação \\
\hline $\begin{array}{l}\text { - facilidade de } \\
\text { controlar todas as } \\
\text { etapas de projeto }\end{array}$ & $\begin{array}{l}\text { - porcentagem de tarefas } \\
\text { completadas na primeira } \\
\text { tentativa } \\
\text { - porcentagem de tarefas } \\
\text { completamente preenchidas e } \\
\text { finalizadas }\end{array}$ & $\begin{array}{l}\text { - tempo de inserção de } \\
\text { informações na primeira } \\
\text { tentativa }\end{array}$ & $\begin{array}{l}\text { - Taxa de uso adesão } \\
\text { voluntária }\end{array}$ \\
\hline $\begin{array}{l}\text { - facilitar o trabalho } \\
\text { dos componentes } \\
\text { envolvidos na } \\
\text { gestão de design }\end{array}$ & $\begin{array}{l}\text { - porcentagem de usuários } \\
\text { completando as tarefas com } \\
\text { sucesso } \\
\text { - porcentagem de tarefas }\end{array}$ & $\begin{array}{l}\text { - eficiência relativa em } \\
\text { comparação à gestão } \\
\text { sem uso de um sistema }\end{array}$ & $\begin{array}{l}\text { - freqüência de reuso } \\
\text { - freqüência de acesso ao } \\
\text { sistema }\end{array}$ \\
\hline - agilizar o processo & $\begin{array}{l}\text { - porcentagem de tempo } \\
\text { execução das tarefas reduzida } \\
\text { pelo uso do sistema } \\
\text { - número de tarefas reduzidas } \\
\text { pelo uso do sistema }\end{array}$ & $\begin{array}{l}\text { - tempo gasto no } \\
\text { preenchimento de } \\
\text { apenas uma ferramenta } \\
\text { de gestão }\end{array}$ & $\begin{array}{l}\text { - taxa de satisfação em } \\
\text { relação ao tempo de } \\
\text { execução das tarefas no } \\
\text { sistema }\end{array}$ \\
\hline $\begin{array}{l}\text { - facilitação e } \\
\text { melhoria no } \\
\text { processo de design }\end{array}$ & - número de erros reduzido & - tempo de etapas & $\begin{array}{l}\text { - escala de satisfação em } \\
\text { relação a facilitação do } \\
\text { trabalho }\end{array}$ \\
\hline $\begin{array}{l}\text { - menor incidência } \\
\text { de erros }\end{array}$ & $\begin{array}{l}\text { - porcentagem de erros } \\
\text { corrigidos pelo sistema }\end{array}$ & $\begin{array}{l}\text { - tempo gerado pelos } \\
\text { erros }\end{array}$ & $\begin{array}{l}\text { - taxa de stress pelo } \\
\text { esquecimento }\end{array}$ \\
\hline $\begin{array}{l}\text { - trazer maior } \\
\text { satisfação na }\end{array}$ & $\begin{array}{l}\text { - porcentagem de tempo } \\
\text { dedicado ao preenchimento }\end{array}$ & - tempo de uso & $\begin{array}{l}\text { - taxa de uso } \\
\text { - escala de satisfação em }\end{array}$ \\
\hline
\end{tabular}




\begin{tabular}{|l|l|l|l|}
\hline $\begin{array}{l}\text { execução das } \\
\text { tarefas da gestão de } \\
\text { design }\end{array}$ & $\begin{array}{l}\text { burocracia em comparação com } \\
\text { metodologias anteriores }\end{array}$ & $\begin{array}{l}\text { relação à execução das } \\
\text { tarefas com o uso do } \\
\text { sistema }\end{array}$ \\
\hline
\end{tabular}

Fonte: Adaptado da NBR ISO 9241-11

Os princípios de usabilidade de Jordan (1998), delineiam como cada item pode afetar a usabilidade em uma interface. A especificação das exigências baseadas nos princípios de usabilidade colaboram para uma concepção de produto centrado no usuário e no conforto de seu uso. As exigências de usabilidade foram obtidas por meio das reuniões de grupos focais, com integrantes da gestão de design do caso estudado. A seguir, a tabela apresenta as especificações para o projeto da ferramenta de suporte à gestão de design:

Tabela : Especificações de exigências de usabilidade para a interface

\begin{tabular}{|c|c|}
\hline Princípio & Especificação de exigências para interface \\
\hline $\begin{array}{l}\text { 1. Consistência: Projetar um produto de } \\
\text { maneira que as tarefas similares sejam feitas } \\
\text { de maneiras similares. }\end{array}$ & $\begin{array}{l}\text { - Navegação similar em módulos e telas diferentes; } \\
\text { - Iconografia e elementos gráfico com um padrão visual; } \\
\text { - Efeitos sonoros, visuais e textuais similares para atividade, } \\
\text { retornos da mesma categoria; }\end{array}$ \\
\hline $\begin{array}{l}\text { 2. Compatibilidade: Projetar um produto de } \\
\text { maneira que o método para operá-lo seja } \\
\text { compatível com a expectativa do usuário } \\
\text { baseado no conhecimento de outros tipos de } \\
\text { produtos e do mundo real. }\end{array}$ & $\begin{array}{l}\text { - Usar referência de criação/exclusão/edição de documentos } \\
\text { existentes em softwares na operação dos projetos; } \\
\text { - Usar referencial de cores vermelho, verde e amarelo para } \\
\text { status de projetos; } \\
\text { - Usar uma agenda com os dias da semana para mostrar a } \\
\text { programação dos projetos pessoais; }\end{array}$ \\
\hline $\begin{array}{l}\text { 3. Capacidade: Projetar um produto de } \\
\text { maneira que se leve em conta a demanda } \\
\text { das habilidades do usuário requeridas } \\
\text { durante a interação. }\end{array}$ & $\begin{array}{l}\text { - Possibilidade de uso por pessoas com mobilidade reduzida } \\
\text { e surdez; } \\
\text { - Usar estímulos visuais para chamar atenção para } \\
\text { ocorrências importantes em telas com muitas informações; } \\
\text { - Levar em consideração usuários com experiência } \\
\text { intermediária a avançada no uso de sistemas digitais; } \\
\text { - Lembrar o usuário sobre ações ou atividades que precisam } \\
\text { de atenção em relação ao prazo, à falta de inserção de } \\
\text { informação, ao excesso de horas dedicadas etc. }\end{array}$ \\
\hline $\begin{array}{l}\text { 4. Retroalimentação: Projetar um produto de } \\
\text { maneira que as ações tomadas pelo usuário } \\
\text { sejam reconhecidas e uma indicação } \\
\text { significativa seja dada sobre os resultados } \\
\text { dessas ações. }\end{array}$ & $\begin{array}{l}\text { - Fornecer um retorno após execução de ações (sonoros, } \\
\text { visuais e/ ou textuais); }\end{array}$ \\
\hline $\begin{array}{l}\text { 5. Prevenção ou correção de erros: Projetar } \\
\text { um produto de maneira que a probabilidade } \\
\text { de erro deve seja minimizada e, então, se os } \\
\text { erros realmente ocorrerem, que sejam } \\
\text { recuperados de forma rápida e fácil. }\end{array}$ & $\begin{array}{l}\text { - Possibilidade de reverter ações tomadas inadvertidamente; } \\
\text { - Mensagens confirmando ações com resultados } \\
\text { determinantes (exclusão, fechar programa etc.); } \\
\text { - Fornecer explicativos sobre os botões de ações para } \\
\text { instrução do usuário; } \\
\text { - Usar termos e ícones relevantes para as ações executadas; }\end{array}$ \\
\hline $\begin{array}{l}\text { 6. Controle do usuário: Projetar um produto } \\
\text { de maneira que o usuário tenha o máximo }\end{array}$ & - Possibilidade de customização da interface do usuário; \\
\hline
\end{tabular}




\begin{tabular}{|l|l|}
\hline $\begin{array}{l}\text { controle possível sobre as ações tomadas no } \\
\text { produto. }\end{array}$ & \\
\hline $\begin{array}{l}\text { 7. Clareza visual: Projetar um produto de } \\
\text { maneira que a informação apresentada seja } \\
\text { lida de forma rápida e fácil, sem causar } \\
\text { confusão. }\end{array}$ & $\begin{array}{l}\text { - Sintetizar informações e menus por meio de iconografia; } \\
\text { - Usar ícones relevantes para as ações executadas e para o } \\
\text { contexto dos usuários; } \\
\text { - Usar elementos gráficos como formas, cores, hierarquia, } \\
\text { ritmo etc. como síntese de informação }\end{array}$ \\
\hline $\begin{array}{l}\text { 8. Priorização da funcionalidade e da } \\
\text { informação: Projetar um produto de maneira } \\
\text { que a funcionalidade e a informação mais } \\
\text { importantes sejam facilmente acessadas pelo } \\
\text { usuário. }\end{array}$ & $\begin{array}{l}\text { - Evitar muitos "clicks" para chegar a uma determinada } \\
\text { informação (no máximo } 3 \text { níveis); } \\
\text { - Usar de recursos visuais para setorizar e hierarquizar } \\
\text { informações; }\end{array}$ \\
\hline $\begin{array}{l}\text { 9. Transferência adequada de tecnologia: } \\
\text { Projetar um produto de maneira que se faça } \\
\text { uso adequado de tecnologias desenvolvidas } \\
\text { para outros contextos para aumentar a } \\
\text { usabilidade do produto. }\end{array}$ & $\begin{array}{l}\text { - Usar linguagem de programação livre; } \\
\text { - Desenvolver um sistema open source, com código aberto; } \\
\text { - Utilizar modelos de aplicativos livres já existentes; }\end{array}$ \\
\hline $\begin{array}{l}\text { 10. Evidência: Projetar um produto de } \\
\text { maneira que sejam dados indícios de como } \\
\text { ele funciona e o método para operá-lo. }\end{array}$ & $\begin{array}{l}\text { - Usar os mesmos termos das atividades executadas sem um } \\
\text { sistema, para tarefas iguais no sistema; } \\
\text { - Ter analogias com outros sistemas/ softwares de } \\
\text { conhecimento de usuários intermediários (email, editor de } \\
\text { texto, websites etc.); } \\
\text { - Comandos auto-explicativos, por meio de caixas de diálogo. }\end{array}$ \\
\hline
\end{tabular}

Fonte: Elaborado pelo autor

As medidas de usabilidade, orientadas pela NBR ISO 9241-11, trazem metas reais e numéricas a serem alcançadas com a implementação da ferramenta de suporte a gestão de design. Enquanto que os príncípios de Jordan (1998) orientam para a elaboração de exigência de usabilidade que resultam em especificações importantes para o conforto do usuário no uso da ferramenta e na interação com a interface.

\section{CONDIDERAÇÕES FINAIS}

A partir das interações estabelecidas no contexto de pesquisa e dos requisitos de usabilidade identificados nesta pesquisa, espera-se conseguir identificar as soluções para elaboração do modelo de ferramenta de gestão de design, bem como validar junto aos pesquisados, os executores das tarefas. Com isso, espera-se conceber uma ferramenta que privilegiem 0 conforto e a usabilidade dos usuários no contexto da gestão de design e, além disso, proporcionem maior qualidade no desenvolvimento dos serviços e, se possível, maior economia e redução no tempo das atividades através da organização e acompanhamento de projetos, estratégias e tarefas, usando a ferramenta de gestão de design a ser desenvolvida.

O trabalho de especificar medidas e exigências para usabilidade, envolve mais do que apenas fazer uma análise de um produto ou ambiente. É necessário ter um profundo conhecimento da tarefa, dos usuários, do contexto e do ambiente. É necessário haver grande envolvimento com o estudo e interação com os usuários para iniciar o processo de concepção de um produto ou serviço que seja para a usabilidade. 
Durante a tarefa de especificar o contexto de uso, surgiram ideias para complementar o produto. Isso indica que o processo de concepção é contínuo e que os resultados obtidos ainda vão precisar serem validados novamente com usuários para confirmação dos resultados e ajustes de possíveis novas interações entre a ferramenta e o usuário.

Esta pesquisa ainda visa estudar outros casos de gestão de design para tentar conceber uma ferramenta que seja aplicável a outras situações e ambientes, como pequenos núcleos de design sem fins lucrativos, departamentos de design em empresas, empresa júnior de design entre outros.

\section{REFERÊNCIAS BIBLIOGRÁFICAS}

BEST, Kathryn. Le design management: stratégie, méthode et mise en ouvre. Paris: Pyramide, 2009.

CYBIS, Walter; BETIOL, Adriana Holtz; FAUST, Richard. Ergonomia e usabilidade: conhecimentos, métodos e aplicações. 2.ed. São Paulo: Novatec Editora, 2010.

GIL, A. C. Como elaborar projetos de pesquisa. São Paulo: Atlas, 2010.

GIMENO, J. M. I. La gestión del diseño en la empresa. Madrid: McGraw-Hill, 2000.

NBR 9241-11. Requisitos ergonômicos para trabalho de escritórios com computadores: orientações sobre usabilidade. Rio de Janeiro: ABNT, 2002.

JORDAN, P. W. An Introduction to Usability. Londres: Taylor \& Francis Ltda., 1998.

MOZOTA, Brigitte Borja de. Design management: using design to build brand value and corporate innovation. New York, 2003.

SILVA, Carina Scandolara da. Abordagem sistêmica com foco na gestão de design sustentável [dissertação]: o caso Nuovo Design. Orientador, Luiz Fernando Figueiredo. Florianópolis, SC, 2012. 